\title{
Development and Delivery of an Integrated Project-Based Jobsite Management Undergraduate Course
}

\author{
Philip L. Barlow, M.S., CCC, DBIA, LEED AP \\ California Polytechnic State University \\ San Luis Obispo, California
}

\begin{abstract}
At universities offering professional degrees, such as construction management, some programs are moving towards and exploring alternative delivery methods for achieving the curriculum's goals and objectives. This article describes an integrated and project-based learning Jobsite Construction Management course being taught at a major university. A course overview describing the various delivery methods used (such as lectures, reading assignments, supplemental materials, guest lecturers, lab assignments, technology, and jobsite visits) is presented. The benefits of vertical and horizontal course integration in a project-based learning environment are emphasized and more fully explained. A class survey was conducted over two quarters to assess the student's perspective on various aspects of the course, in particular the delivery methods used to relate course material. The student survey responses are evaluated and discussed individually. Results suggest that an integrated curriculum set in a project-based learning environment utilizing various delivery methods can produce positive results from a student's perspective.
\end{abstract}

Key Words: Jobsite Management, Project-Based Learning, Integrated Course, Delivery Methods, Construction Education

\section{Introduction}

Over the years there has been a continued and growing interest in using alternative teaching and learning techniques at academic institutions which offer professional degrees (Senior, 1998). The discipline of construction management clearly fits this professional educational model. The art of construction management includes integrating the conflicting demands of clients, architects, engineers, various government entities, and end-users into a balanced and reconciled project solution which meets budget, schedule, quality, and safety prerequisite criteria. With this goal in mind, students should be encouraged by the classroom experience to utilize basic construction management skills to craft integrated construction project solutions. Non-traditional pedagogical approaches should be considered to successfully prepare students to become professionals in the construction industry (Hauck \& Jackson, 2005). Of the many possible pedagogical approaches which might be used to achieve such an outcome, this paper primarily focuses on curriculum integration, project-based learning, and varying class delivery methods as a basis to achieve classroom success. "Great learning occurs when students are put in situations outside the curriculum norm, situations which make them a bit uncomfortable and challenge them in new ways" (Barlow, 2009, p.6). This paper seeks to determine whether an integrated course which leverages a project-based learning environment has the opportunity of creating such a learning experience for undergraduate students in construction management courses.

\section{Integrated Curriculum}

Most construction management undergraduate programs teach core subjects such as scheduling, estimating, controls, and contracts in a series of standalone courses which are typically delivered in a lecture format (Chinowsky, et al, 2006). Each course is treated as an isolated set of concepts and problem-solving strategies termed "knowledge compartmentalization" (Albano \& Salazar, 1998). This segmented organization of the curriculum relies on students to "connect the dots" themselves, often struggling unsuccessfully to make the associations and functional integration required to effectively grasp the overall construction process (Hauck \& Jackson, 2005; Bertz \& Baker, 1996; Albano \& Salazar, 1998; and others). While the traditional curriculum structure may have proven successful over the 
years, many construction management and engineering undergraduate programs have begun to identify its limitations and question its effectiveness. The traditional approach may simplify the problems of teaching in a university environment, but it sacrifices the discussions and understanding of the interrelationships among these elements (Senior, 1998).

Developing a more integrated undergraduate curriculum is an effort by educators to step away from the "traditional model” and be more in line with today's architectural, construction, and engineering (ACE) industry. Students today are expected not only to know and understand the basics of their discipline, but also to perform efficiently and effectively in a multidisciplinary and fully integrated design and construction environments (Albano \& Salazar, 1998). An integrated course must capture the imagination of the students, be perceived as important by learners, legitimize the disciplinary content which is being integrated, and accommodate a variety of learning approaches (Barab \& Landa 1997).

Many institutions have attempted to partially rectify this situation by developing and incorporating a capstone course into the construction curriculum in the student's senior year. This is done specifically to help students fit the individual "puzzle pieces" together at the end of their undergraduate education career. Polytechnic institutions such as California Polytechnic State University and Virginia Polytechnic Institute have both written about the need to integrate the curriculum vertically (Hauck \& Jackson, 2005; Mills, Auchey, \& Beliveau, 1996). Virginia Polytechnic has been teaching a senior capstone course for twenty years and believed it was "time to integrate that experience across the curriculum in a vertical sense” (Mill, Aucthey, \& Beliveau, 1996, p.35). The definition of vertical integration is the extension of a horizontally integrated curriculum throughout, not just at the end of the student's educational experience. Chinowsky et al (2006) emphasized further that analytical thinking inclusive of creativity, leadership, group interaction, and communication should be integrated early and fostered throughout the curriculum.

Over the last five years, the faculty at Cal Poly San Luis Obispo developed, conducted pilot studies, obtained feedback, evaluated, and recently implemented a more fully integrated curriculum based on both horizontal and vertical integration of its curriculum. For more information on the details of this transition from a program wide perspective, see "Design and Implementation of an Integrated Construction Management Curriculum" (Hauck \& Jackson, 2005) and "Pilot Study of an Integrated Construction Management Curriculum” (Montoya, Kelting,\& Hauck, 2009). This paper focuses specifically on the details involving the jobsite construction management course which is one of seven core courses developed as a part of this curriculum integration spread throughout the student's undergraduate studies (Figure 1).

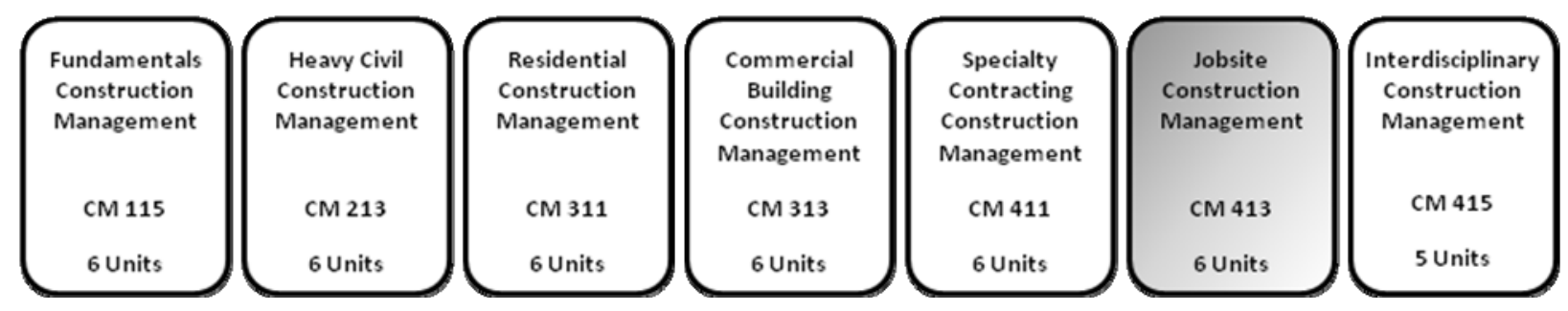

Figure 1 - Cal Poly Integrated Curriculum Core Courses

\section{Project-Based Learning (PBL)}

The "traditional" approach to teaching often involves a four step learning process of lecturing, assigned readings, intermittent homework, and summary testing (Angelides, et al, 2000). While these pedagogical techniques and tools are not abandoned by a more project-based learning (PBL) approach, they are deemphasized, supplemented, combined, and in the end enhanced by it. PBL requires students to become active (versus passive) learners, empowering them to learn outside the traditional classroom environment. Combining practical elements into the curriculum of a professional discipline has long been recognized as critically important to student learning (Schon, 1983). William and Pender (2002) stated the following regarding the future structure of construction management teaching: 


\begin{abstract}
"Although the various aspects of construction management (contracts, planning, estimating, and safety) can be taught and assessed separately, they are inextricably entwined in the solution of real-life problems. For this reason, the teaching of construction management is ideally suited to a combination of traditional and problem-based methods of teaching. Where the traditionally taught classes permit the efficient delivery of basic knowledge, problem-based learning classes provide the opportunity for synthesis of knowledge, development of skills (soft), and the possibility of developing innovative solutions....” (p.19).
\end{abstract}

Learning, as described by modern cognitive psychology, is the use of existing base knowledge to build new knowledge (Gijselaers, 1996). Through PBL we are connecting theory (existing base knowledge) with a simulated reality (new knowledge) and applying it in the classroom, thus matching Gijselaers' fundamental structure of learning. In PBL we are giving students an ability to construct their own knowledge landscapes through the development and implementation of contextual situations in which they can apply content (Chinowsky et al, 2006). In addition, Gijselaers emphasized that when new knowledge is gained it is placed into a network of related concepts called a semantic network. The manner in which these networks are organized determines how readily information can be recalled and applied (Gijselaers, 1996). PBL helps create the "associations needed between theory and practice to enable students to better retrieve the pertinent theoretical knowledge when faced with real problems" (Chinowsky, et al, 2006, p.119).

PBL emphasizes the critically important "soft skills" of construction management which are often built "on top of" the technical skills developed in traditional individual classes. Thamhain (1992) acknowledged thirty potential problems which might inhibit a construction project from being successful, none of which could be classified as technical incompetence. Thamhian concluded that the lack of soft skills such as teamwork, leadership, communication, conflict resolution, and upper management involvement were the main cause of poor project performance. This contention was confirmed by several other studies which question the value of technical and cognitive skills over emotional intelligence and business-related skill sets (Kemper, 1999; Odusami, 2002; and others). Gunderson, Barlow, and Hauck (2007) conducted a study on construction superintendent skill sets to help guide the development of postsecondary curricula. Their study stressed the importance of people skills such as communication, trust, and dealing with various personality types; these attributes ranked highest amongst the respondents. Linking the development and enhancement of these critical soft skills in construction management undergraduate students through project-based learning is beginning to come into focus. Sirotiak and Walters (2009) concluded from their research that students through a PBL class experience demonstrated a measureable enhancement in their soft skills relating to confidence and stress coping. The evidence is building that project-based learning is an exceptional and unique tool to help students grasp the important non-technical skills needed to succeed in the business of construction management.

\title{
Project-Based Learning and Integrated Curriculum (PBL/IC)
}

When looked at together, the lines of project-based learning and an integrated curriculum (PBL/IC) start to become blurred. The combination of these two concepts is an opportunity to reverse the trend of focusing on particular construction management skills individually. Skills such as estimating, scheduling, controls, and contracts (Chinowsky, et al, 2006) combined under a project-based learning umbrella more fully integrates the subject matter. PBL/IC allows the student to explore and draw upon all the individual technical experience they have developed, apply it to a (safe and controlled) construction project environment, and continue the development of the critical soft skills necessary for business success. An integrated curriculum taught in a project-based learning environment can reintroduce breadth and depth into the "traditional" construction management curriculum.

This paper introduces and discusses a newly developed construction jobsite management course which is integrated, project-based, and employs several different teaching techniques and delivery methods to achieve student learning. The various delivery techniques employed are discussed as to how they were applied to, refined, supported, and complemented an integrated curriculum anchored in project-based learning. The course was offered and taught during the Winter and Spring quarters of 2010 at the California Polytechnic State University of San Luis Obispo.

Jobsite Construction Management Course Development 
William and Pender (2002) identified two key problems to successfully developing a project/problem-based learning environment. First, there are time limitations which exist within a typical university lecture course. Second, the significant increase in student-teacher contact time required with a more one-on-one format must be considered. To meet these challenges, the Cal Poly construction management department reformatted the entire curriculum to address the time limitation issue by creating seven high credit hour core courses as referenced in Figure 1 . This created the class time needed not only to integrate the expanded class material, but also to immerse the students in a project-based class experience. This combined with 16 hours per week of formal teacher-student contact hours and twenty four hour access to the classroom time limitations on conducting a PBL course were greatly mitigated.

In addition to reorganizing the curriculum, the department was also successful in raising the funds necessary to construct a new building. The classroom spaces were designed and built specifically for an integrated and projectbased teaching model. This non-traditional classroom space was developed to address William and Pender's second concern, student-teacher contact time. The design included a central lecture area surrounded by individual and dedicated student work spaces, encouraging students to remain and work in the classroom. This was particularly important to project-based learning as group projects and student interaction are essential to success. The classroom also was designed with a dedicated and physically attached teacher work room for each class. This allowed the professor to be present and readily accessible to students during the entire class period, thus encouraging and facilitating student-teaching contact time. With the physical classroom environment and extensive time requirements solved by the department, it was up to the individual professors of these seven core courses to properly develop (in concert with one another) a fully integrated project-based classroom experience.

\section{Course Philosophy and Development}

Barab and Landa (1997) raise four essential questions which need to be continually asked and answered during the development and implementation of any integrated course:

1. Will the course provide a diversity of learning opportunities which encourage the student to attempt difficult tasks and learn new skills in a motivating and rewarding context?

2. What happens to the structure of the individual disciplines which are incorporated in the integrated class?

3. What happens to the school schedule and how does it have to change to accommodate an integrated course?

4. How can teachers find the time to develop and implement an integrated curriculum?

While some of the issues listed by Barab and Landa (1997) have been previously addressed, it was up to the individual instructor to manage and shape each individual core course in the best way they saw fit, while still achieving the goals and objectives of the class as established by the department. The general aspirations of this course, in addition to the very specific department course goals and objectives, included challenging the students to achieve in the areas of:

- Presentation and communication skills

- Collaborative and inter-personal skills

- Creativity and forward-thinking abilities

- Teamwork and problem solving skills

- Active-learning and creative problem solving

- Self-learning and time management

\section{Course Overview}

The jobsite construction management course has been taught at this university for many years as a required three unit lab class during the student's third academic year. With the department's new integrated curriculum fully implemented in late 2009, the class was altered to a six unit core course. Taught in the students fourth year, this class integrated portions of the core subjects which no longer existed individually. The subjects listed below were integrated into the course in addition to its original goals and objectives.

- Estimating (generally the process of pricing changed work)

- Controls (generally the maintenance of updating of a master schedule w/ look-ahead schedules)

- Contracts (generally the affects of contract provisions on jobsite construction activities)

- Temporary Structures (generally the non-permanent elements which facilitate the construction process) 
While a pilot version of this course was taught in the Summer of 2009, Winter and Spring 2010 were the first two times this course was taught as intended by the department. The average class size was 22 to 24 senior undergraduate construction management students. Because this class was listed as an optional course for minors, it consistently attracted two or three architecture and/or architectural engineering students. This was viewed positively, as the course was ideal for such students and allowed the instructor an opportunity to advance interdisciplinary opportunities.

Student retention has been greatly enhanced when several different learning modes are combined and incorporated into the delivery of class content (Wankat \& Oreovicz, 1993). Thus the next part of this paper is a description and evaluation of the several delivery methods utilized to achieve the goals and objectives of the course. These delivery methods included: lectures, reading assignments with pre-quizzes, guest lecturers, supplemental material, a series of lab assignments which supported a capstone project, and student presentations based on construction site field visits.

\section{Lectures}

The course was organized to first provide the tools the students needed to succeed, in order to apply those tools to the project-based aspects of the class. Because the quarter system is based on only a ten weeks session, this further hastened the need to lecture early and often in the beginning weeks of the course. To facilitate the transition from lecture to lab, topics were introduced and discussed in a project-chronological format and then directly linked with the associated project-based lab assignments. This was done so students could almost immediately apply what they had learned in lecture to the class project. The following sequences of topics were taught in the first six weeks of the course:

- $\quad$ Project Teams

- Construction Documents

- Computer Software Training (Prolog, Revit, \& ArchiCAD)

- Progress Meetings

- Safety Management and Record Keeping

- Subcontracts and Purchase Orders

- Submittals

- Changes and Claims

- Time and Cost Control

- Jobsite Layout and Labor Relations

- Project Quality Management

- Progress Payments and Project Close-out

The lecture material was presented in power point format and posted on the course website after the lectures were completed. There are varying opinions on the subject of posting power point slides. This author found that posting slides after a lecture kept the material novel when first presented, motivated the student to pay more attention during the lecture, encouraged them to interact and discuss the subject more freely, and allowed students the opportunity to review the slides prior to an examination. Once the basic and essential jobsite management material was disseminated, the information was then utilized by the students throughout the rest of the quarter as part of their ongoing project lab assignments (described later). As it relates to lecturing, the last four weeks of the quarter are more leisurely spent exploring topics which included: jobsite temporary structures, jobsite productivity, construction learning curve, lean construction techniques, sustainable construction practices, leadership, managing people, and earned-value management.

\section{Reading Assignments and Pre-quizzes}

There was one required textbook for the class, it was written by Minks and Johnston entitled Construction Jobsite Management, $2^{\text {nd }}$ edition, John Wiley \& Sons, New York, 2004. The text book subject matter was relevant and well suited for a construction management undergraduate course. The chapters in the book, while needing some rearrangement, matched well with the topics identified in the first six weeks. The chapter reading assignment was relevant to that day's lecture topic and was due prior to class discussion. The course syllabus identified when each topic would be discussed and linked it to a chapter in the book. It was the student's responsibility to read the assigned chapter prior to attending the class lecture. This facilitated a more meaningful and in-depth discussion of 
the subject matter. A pre-quiz was administered at the beginning of class to reward students who complied. The format was a simple; five questions, five minutes, a multiple choice quiz which simply confirmed the student had at least scanned the material. The grade significance of the quiz was low, but enough to motivate students to pick up the book (see instructor assessment described later).

\section{Supplemental Materials}

Since the textbook only covered six tenths of the course, supplemental readings and lecture materials were developed for the remaining topics of the class. In addition, a variety of selected readings were chosen from current construction industry trade magazines (ENR, Cost Engineering, Construction Executive, etc). These articles were read, vetted, scanned, and posted to the class website for ease of access and utilization by the students. This database of material, which continually grows, allowed the students to pursue various topics of interest which also related to the goals and objectives of the course. Students were required to write a one-page summary of the readings chosen and present their findings to the rest of the class.

\section{Guest Lecturers}

Over the two quarters of Winter and Spring 2010, a number of guest lecturers from the construction industry were brought in and spoke with the class. Because of the remote location of the university, it has been traditionally difficult to persuade and consistently engage industry experts in the classroom. Guest lecturers were primarily recruited industry veterans and alumni who were already coming to campus recruiting for their company. This type of industry engagement helped strengthen the relationship between students, the department, and our construction industry partners. This kind of arrangement also made formal, structured, timely, topical, and readied material which can be directly applied to the course difficult to orchestrate. Prior to the guest lecturers' visit, extra efforts were taken by the instructor to inform and guide the topics discussed to match with what the students were currently studying. Often the field experience of the lecturer combined with assistance from the instructor brought new discussion points and a fresh perspective to class subject matter. Instructor participation and engagement was vital during an industry expert's visit to facilitate a more meaningful dialogue and assist students in making the connections to previously presented class material.

\section{Lab Assignments supporting Project-Based Learning}

The construction project utilized during these two quarters, as a foundation for project-based learning (PBL) in the class, was the Simpson Strong-Tie Building. This building was chosen because a complete set of contract documents was available, the building was relatively simple, had some interesting structural elements, and happened to be under construction during this time period. The myriad of pedagogical advantages to using an active construction site on campus need not be listed here. With a project selected, it was the task of the instructor to design the lab assignments in such a way which corresponded with the lectures and simulated the construction process (as realistically as possible) in the classroom.

The class project was compressed from a ten month construction schedule to ten weeks. Each individual student was assigned a subcontractor's role for the entire quarter. A rotating group of three students were assigned as the general contractor each week. Each general contractor group was responsible for the construction administration of the project for their assigned week. Their tasks (each week) included a subcontractor and owner progress meeting, dealing with simulated jobsite problems, and scheduling updates and maintenance. Additional assignments included a detailed three-week look-ahead, jobsite coordination and oversight, quality control of the building model, and complete document control. Each individual student subcontractor was responsible for tasks such as generating requests for information (RFI's), submittals, and physically constructing the model. This type of PBL environment required the instructor to shift from a traditional teacher role, to one of a mentor and resource, and to an all business role as a savvy owner who wanted to follow the procedures of the contract documents to the letter and get his building built.

A series of thirteen labs were assigned to the students soon after each topic was fully presented and discussed in class. Each lab required the students to perform an activity which supported the PBL goals. The (I) indentifies that 
the lab was performed by each individual student, assigned as a separate subcontract. The (G) was an assignment for each general contractor group, typically three to four students per group:

1. Ethics (I): The student identified (on-line) a “code-of-ethics” list from at least five individual construction related professional organizations and wrote a paper on the three individual codes with which the student found compliance most difficult.

2. 10 Hour OSHA (I): Through "Click-Safety” (an online safety course), students completed the 10-hour OSHA safety class and turned in their certificate.

3. Tool Box Talk (I): At the beginning of each class period, a student prepared and presented a 10-15 minute CalOSHA tool box talk to the class, simulating (as closely as possible) an actual field experience.

4. Familiarization (G): A straight forward "Where's Waldo" exercise familiarized the students with the construction project contract documents.

5. Subcontractor Agreement (I): The student wrote a complete subcontract agreement using the AGC short as a template. The exercise emphasized the scope-of-work and was accompanied by an appropriate certificate of insurance.

6. Submittal (I): Per the contract documents, the student generated a submittal package specific to their trade. This included some type of product data, MSDS sheets for that product, and a submittal transmittal.

7. 20-Day Preliminary Notice (I): In California a preliminary notice must be filed with the owner and the lender to protect a subcontractor's lien rights. The student filled out this form as an administrative function but had to comply with the particular time and procedural requirements.

8. Claim (I): Each student subcontractor submitted two RFIs -- one representing an owner credit (value engineering) and one subcontractor/contractor cost increase which was subsequently turned into a fully priced potential change order.

9. Cost Control (I \& G): Student subcontractors created a detailed cost control budget based on their lump sum price and scope-of-work. This exercise was then extrapolated to the student general contractors.

10. Planning (G): Now that the student was sufficiently familiar with the project, project-specific planning was considered regarding sustainability, risk management, material handling, temporary structures, etc.

11. Quality (I): Again, being sufficiently familiar, students considered quality control checklists, building codes, and industry standards which apply to their particular trade.

12. Progress Payment (G): A pay application was generated by each student general contractor group. Formatted to the AIA G701 and G702, it included a detailed schedule of values (SOV) and a varying payment date so each group submitted a unique pay request.

13. Project Close-out (G): To better understand the close-out process, each student general contractor group reviewed a section of the contract document requirements for warranty, training, stock material, etc.

An interesting aspect of these labs was that many did not have set due dates. Instead many labs were due as a natural progression of the project schedule. This proved to be particularly vexing to many of the students who were used to a more structured environment. For instance, the subcontractor agreement and submittal package had to be fully executed prior to the subcontractor (student) entering the jobsite (model). This required the student to closely monitor the jobs progress, and generate their paperwork in a timely manner. They also had to account for the time and effort required to have these documents processed and fully executed by all the other parties involved.

\section{Utilizing Technology}

As with most professional disciplines, university course improvements are needed continuously (particularly in technology) to meet the demands of an ever progressing construction industry. Two years ago the jobsite construction management course progressed from excel spreadsheets and is now using Meridian Systems - Prolog Management Software to create and track the project's paperwork. Prolog has been the most widely used prepackaged construction management software in our industry. Utilizing this software exposed students to an industry standard and added an element of realism to the project. More recently, the class went from physically building the model in a wood box of soil to now building the model virtually in both a Revit and AutoCAD computer format (See Figure 2). 


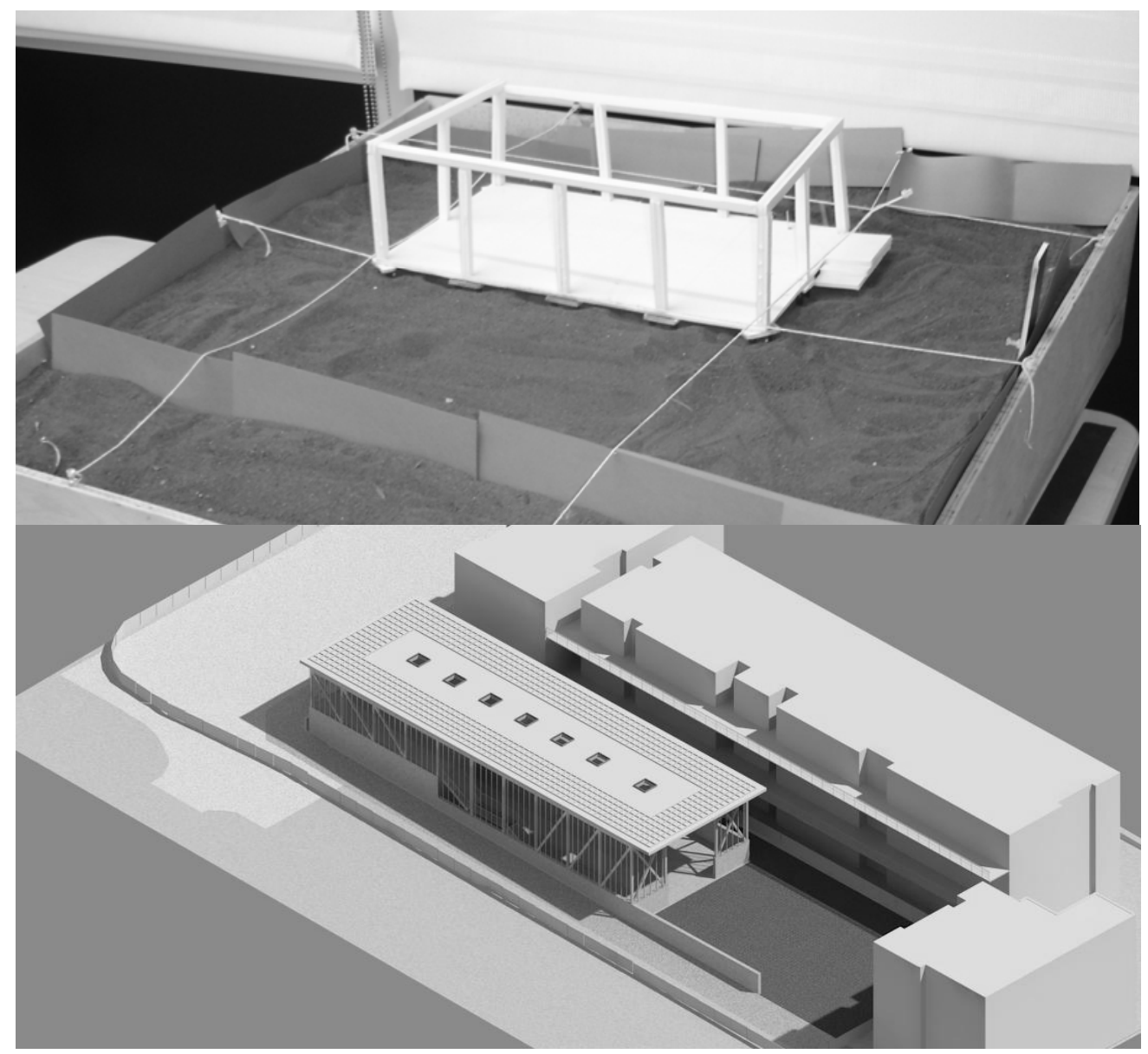

Figure 2. Example of a previous physical model and a current virtual model.

\section{Construction Project Jobsite Visit - Student Presentations}

As a final project the students were asked to pair-up, identify a "significant" active construction project, and conduct a site visit with the goal to present their findings to the class. This assignment was given to the students on the first day of class as the logistics of finding a work day which the students could visit the site has traditionally been problematic. The assignment was clearly structured and project goals clearly delineated so it matched well with the learning objectives of the class. The site visit included two interviews with the onsite superintendant and project manager, an analysis of the project team (including the owner, architect, inspector, etc.), a complete investigation of the jobsite paperwork process (contracts, document processes, etc.), and the identification and analysis of two working temporary structures. The information gathered by each team was then presented to the rest of the class in a combined power point and video format. This exercise allowed the students to affirm on their own that the PBL assignment in class paralleled those conducted on actual construction projects.

\section{Instructor Assessment}

The following was criteria used to assess the students' performance:

- Reading (Pre-Quizzes) 10\%

- $\quad$ Exam 1: $15 \%$

- Exam 2: $15 \%$

- Lab Assignments: $\quad 30 \%$

- Jobsite Visit - Student Presentation $\quad 20 \%$

- Class Participation $\quad 10 \%$ 
The biggest challenge for the instructor, aside the set-up time required to provide the students with a meaningful and technically accurate PBL environment, was the task of grading. The goal of swift and quality instructor feedback was important to student learning and assessment. Assessment was based on a variety of tasks and learning outcomes. While students were mostly graded individually, on occasion some group assessment was necessary. The potential problems which arise from group project assessment are self evident. In these situations students were given the opportunity to submit self and peer evaluations to ensure that group responsibilities were equally shared.

\section{Student Perspectives of the Course Delivery System}

A student survey of the construction jobsite management course was conducted in the Winter and Spring quarters of 2010. The questionnaire was created to assess the delivery systems utilized in an integrated class grounded in project-based learning. The survey was developed in concert with two previous surveys, one conducted in 2006 (Olbina, 2008) and another in 2008 (Kelting \& Hauck, 2010). The goal of this survey (similar to these previous surveys) was to obtain feedback from the students, ensure the delivery systems being used were effective, and improve in areas identified. The questions generally evaluated how well the course did in achieving the learning objectives, the effectiveness of the delivery systems utilized, and how various aspects of the course facilitated the student's learning experience. The survey utilized a Likert type grading rating scale of 1 to 5 ( 1 being the lowest grade and 5 being the highest). In the Winter of 2010, the class consisted of 23 students of which 18 students participated. In the Spring of 2010, the class consisted of 22 students and all 22 returned the survey. The survey was voluntary and conducted anonymously.

Table 1 (See Appendix A) shows the detailed results of the survey with the question number, the question posed, and the percentage score for each grading scale. The results under each scale of 1 to 5 are expressed by the frequency of responses as a percentage of the students that gave each particular grade for that specific question. The "Mean" column is the average values of the grades obtained for the specific questions in that particular term. Figure 3 represents, in graphic form, the relative scoring by question as identified by the mean score of the two classes and the average mean score for the two quarters combined.

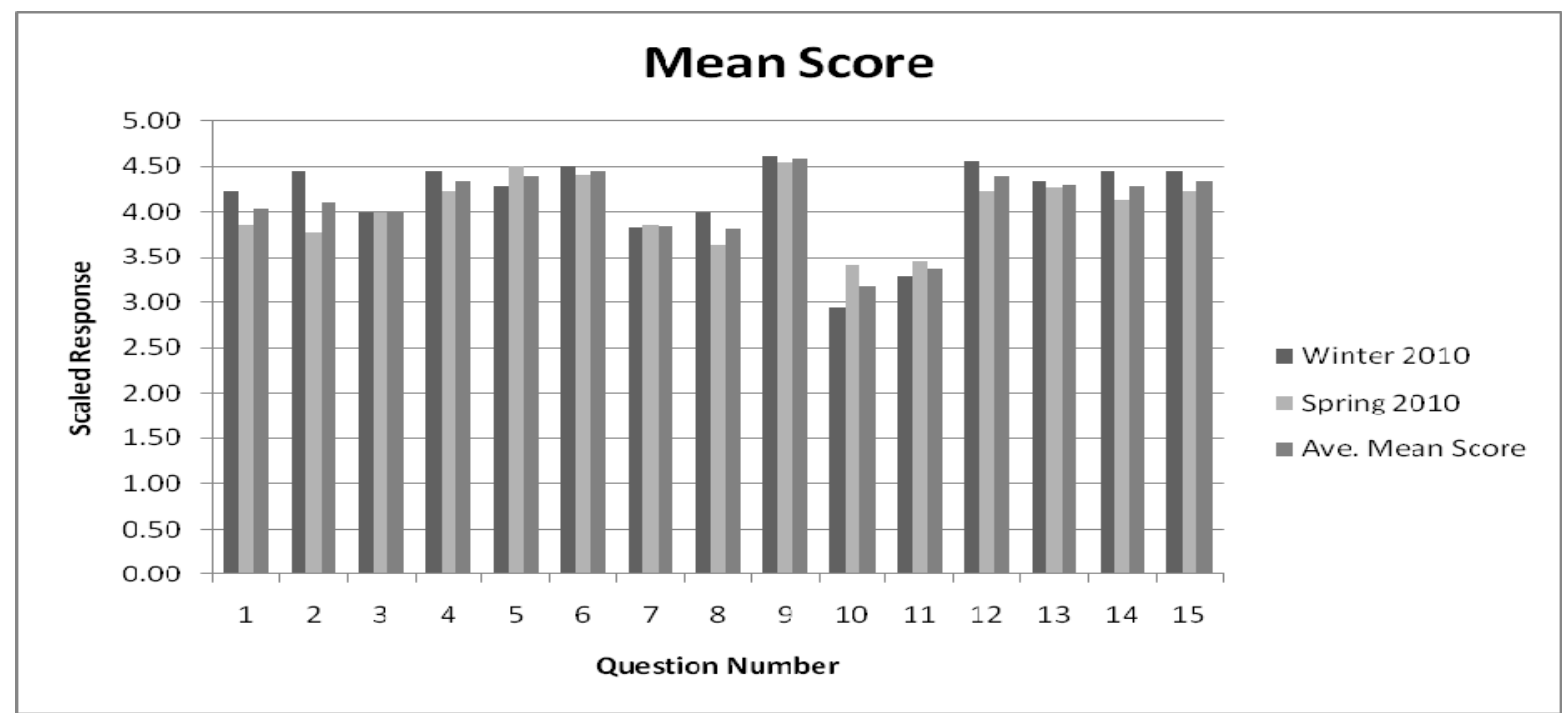

Figure 3 - Mean Score (Winter 2010, Spring 2010, and Average) for Each Question

\section{Discussion of Survey Results}

The author performed the following tasks to analyze the results of each question:

- Evaluation of the average frequency of responses.

- Evaluation of the relative average mean response value.

- Noteworthy discussion of results. 
Due to the consistency of student's responses (see Figure 3) to the same questions each quarter, a comparison of the frequency or the mean values from quarter to quarter was unnecessary. The "values from 4 and 5 were considered positive, 3 was considered neutral, and 1 and 2 were negative" (Oblina, 2008 p.55). The following results were derived from the student evaluations using the methodology stated above:

1. How well did working in a team environment help improve your communication skills? A grade of 4 or 5 was given by $74.0 \%$ of the students who responded to this question. With a mean average score of 4.04 , this ranked $10^{\text {th }}$ out of 15 the questions.

These responses tend to indicate that the students recognized an increase in their communication skills as a result of working in teams but did not consider it a top priority of the course.

2. How well did working in a team environment help improve your teamwork skills?

A grade of 4 or 5 was given by $76.3 \%$ of the students who responded to this question.

With a mean average score of 4.11 this ranked $9^{\text {th }}$ out of 15 the questions.

These responses tend to indicate that the students recognized an increase in their teamwork skills as a result of working in teams but did not consider it a top priority of the course.

3. How well did working in groups help you learn about setting the proper expectations with your peers?

A grade of 4 or 5 was given by $79.8 \%$ of the students who responded to this question.

With a mean average score of 4.00 , this ranked $11^{\text {th }}$ out of 15 the questions.

These responses tend to indicate that the students recognized an increase in the proper setting of expectations as a result from working in groups but did not consider it a top priority of the course.

4. How well did the final project help your understanding of the jobsite management process?

A grade of 4 or 5 was given by $90.4 \%$ of the students who responded to this question.

With a mean average score of 4.34 , this ranked tied for $5^{\text {th }}$ out of 15 the questions.

These responses tend to indicate that the construction jobsite project visit was seen as very successful in helping the students understand the management process and an important aspect of the class experience. This connection was likely strengthened by the detailed goals outlined in the assignment but still might be improved.

5. How well did incorporating estimating, scheduling, contracts and temporary structures in one class help with your understanding of the construction process?

A grade of 4 or 5 was given by $94.4 \%$ of the students who responded to this question.

With a mean average score of 4.39 , this ranked tied for $3^{\text {rd }}$ out of 15 the questions.

These responses emphasize the student's understanding of the importance and value of an integrated

curriculum. This relatively strong conclusion likely comes from their exposure to this pedagogy for the past three years.

6. How well did the lab assignments help with your understanding of the course learning objectives?

A grade of 4 or 5 was given by $87.6 \%$ of the students who responded to this question.

With a mean average score of 4.45 , this ranked $2^{\text {nd }}$ out of 15 the questions.

These responses tend to indicate that the lab assignments representing PBL were nearly the most important aspect of the class for connecting theory to practice through active learning.

7. How well did the final project help your understanding of the course learning objectives?

A grade of 4 or 5 was given by $66.9 \%$ of the students who responded to this question.

With a mean average score of 3.85 , this ranked $12^{\text {th }}$ out of 15 the questions.

These responses tend to indicate that a better job needs to be done in connecting the course learning objectives with the construction jobsite project visit assignment. From the instructor's perspective, this assignment seemed to directly support the class goals but better student communication may be needed.

8. How well did the guest lecturers help with your understanding of the course learning objectives?

A grade of 4 or 5 was given by $63.4 \%$ of the students who responded to this question.

With a mean average score of 3.82, this ranked $13^{\text {th }}$ out of 15 the questions.

These responses tend to indicate that there is room for improvement with guest lecturers; possibly limiting the number or establishing a more consistent guest speaker selection. More time might be spent ensuring that guest speaker topics are relevant to current classroom discussions.

9. How well did the teacher lectures help with your understanding of the course learning objectives?

A grade of 4 or 5 was given by $100 \%$ of the students who responded to this question.

With a mean average score of 4.58 , this ranked $1^{\text {st }}$ out of 15 the questions.

These responses tend to indicate the critically important role instructor lectures can play in a student's education. While an all lecture format has obvious negative connotations, it can be utilized effectively in a PBL 
environment. An appropriate mixture of lecture, combined with other varying delivery methods can be successful in an integrated class.

10. How well did the text book help with your understanding of the course learning objectives?

A grade of 4 or 5 was given by $39.4 \%$ of the students who responded to this question.

With a mean average score of 3.18, this ranked $15^{\text {th }}$ out of 15 the questions.

These responses tend to indicate that the text book, while still viewed positively by the students, may be the weakest link in the chain. A new version of the text was recently published and may have a positive impact on the scoring. Solutions might be considered include switching to a new text or developing an electronic text specifically tailored for this course. Expanding the text would also assist in coving the topics in the last four weeks of the course.

11. How well did the reading pre-quizzes help with your understanding of the course learning objectives? A grade of 4 or 5 was given by $38.9 \%$ of the students who responded to this question.

With a mean average score of 3.37 , this ranked $14^{\text {th }}$ out of 15 the questions.

These responses tend to indicate that the pre-quizzes were not popular with the students. Though the practice of pre-quizzes was disliked, it was judged to serve a valuable purpose. Possibly a change in the delivery method with the use of a clicker personal response system might be explored.

12. How well do you expect class field trips would have helped your understanding of the learning objectives? A grade of 4 or 5 was given by $90.9 \%$ of the students who responded to this question.

With a mean average score of 4.39 , this ranked tied for $3^{\text {rd }}$ out of 15 the questions.

These responses tend to indicate that the students would have looked favorably on class field trips to active construction projects. Opportunities have been difficult to uncover due to the remote location of this university, the downturn in the construction market, and the time constraints of the class. Based on this survey, it would appear advantageous to spend more time and resources in this area.

13. How well did the classroom and layout help facilitate your learning experience?

A grade of 4 or 5 was given by $97.2 \%$ of the students who responded to this question.

With a mean average score of 4.30 , this ranked $7^{\text {th }}$ out of 15 the questions.

These responses tend to indicate that the lab classroom design and layout had a positive influence on the student learning. This supports the importance of having a proper classroom setting when conducting a project-based learning course which requires significant student and instructor interaction.

14. How well did the laboratory course environment help facilitate your learning experience (versus lecture)?

A grade of 4 or 5 was given by $92.7 \%$ of the students who responded to this question.

With a mean average score of 4.29 , this ranked tied for $8^{\text {th }}$ out of 15 the questions.

These responses tend to indicate that lab and activity work (versus lecture alone) greatly helped facilitate the students' learning experience. The mediocre ranking of this item may affirm the need for some lecture.

15. How well did the organization of the course help facilitate you learning experience?

A grade of 4 or 5 was given by $92.7 \%$ of the students who responded to this question.

With a mean average score of 4.34 , this ranked tied for $5^{\text {th }}$ out of 15 the questions.

These responses tend to indicate that the course organization had a positive impact on the students' learning

experience. When an instructor diligently prepares and clearly communicates in an organized and well thoughtout manner, the students notice.

\section{Conclusions and Future Research}

The research conducted as a part of this paper identified the delivery methods which the students were most positive about; instructor lecture (1), lab assignments (2), class integration (T3), jobsite field trips (T3), final project (T4), and class organization (T4). While the instructor lectures were fairly customary, the positive student response emphasized the need for a variety of delivery methods which are both appropriate and well prepared. The creation and implementation of the lab assignments are a direct reflection of the PBL environment created by the instructor and were an essential aspect of the class. The integration of core construction curriculum subject matter (scheduling, estimating, controls, and contracts) is decidedly acknowledged and confirmed by the students as a successful pedagogy. Though class jobsite field trips were not conducted, their importance is seen as significant by the students. If class jobsite visits are conducted in the future, their relative importance as a delivery method may be as high or could possibly be listed lower depending on the experience. The final project is a type of small group jobsite visit which was made more valuable by having specific and identifiable learning objectives and outcomes fully communicated to the students. High marks in class organization reflect the quality of the material presented but the importance of detailed preparation. 
The success of this course is predicated on additional class time, increased teacher-student contact hours, traditional dissemination of required technical information, integration of class topics, building of student soft skills, and application of technical information under the umbrella of project-based learning. As this course (and others like it) progress, there are many other kinds of delivery methods which could be considered. As touted by Senior (1998) other enhanced modes of educational delivery methods can include internships, simulation of practice, gaming, casebased instruction, service integration, student follow-ups, and application papers. Instructors should not shy from experimenting and trying new things which might enhance the student's learning experience. As new delivery methods are attempted and integrated into the class, the student survey should be adjusted to measure their relative success.

A potential area for future research may include asking the same (or similar) survey questions in subsequent or similar PBL classes. Many of the questions asked in this survey are similar to those asked in previous research studies, specifically by both Olbina (2008) and Kelting \& Hauck (2010). If more surveys were performed with similar questions or a standard list of questions was developed, a quantitative analysis may be possible comparing these results under varying circumstances. Comparing and contrasting the results of similar surveys which implemented similar or new delivery methods, could prove interesting if tracked over time to identify developing trends. The future is likely to bring a greater need, refinement, and appreciation for professional courses and programs that provide dynamic, challenging, and innovative learning experiences for students.

\section{References}

Angelides, D., Poulopoulos, A., Avgeris, I., \& Haralampous, P. (2000). Case studies and information technology in civil engineering learning. Journal of Professional Issues Engineering Education Practices, 126(3).

Albano, L. \& Salazar, G. (1998). Project-based course for integration of design and construction at WPI. Journal of Professional Issues in Engineering Education and Practice, October 1998, 97-104.

Barab, S. and Landa, A. (1997). Designing effective interdisciplinary anchors. Educational Leadership, March 1997, 52-55.

Barlow, P. (2009). Case study in implementing a service-learning class in a construction management curriculum. Associated Schools of Construction International Proceedings of the $45^{\text {th }}$ Annual Conference, University of Florida Gainesville, Florida. 
Bertz, M. \& Baker, N. (1996). “CELL - a vertically integrated learning resource. Proceedings of the Thired Congress on Computing in Civil Engineering, Anaheim, California, June 1996, 348-354.

Chinowsky, P., Brown, H., Szajnman, A., \& Realph, A. (2006). Developing knowledge landscapes through projectbased learning. Journal of Professional Issues in Engineering Issues and Practice, 132 (2), 118-124.

Gijselaers, W. (1996). Connecting problem-based practices with educational theory. Bringing problem-based learning, to higher education: Theory and practice, L. Wilkerson and W.H. Gijselaers, ed., Josssey-Bass, San Francisco, 13-21.

Gunderson, D., Barlow, P., \& Hauck, A. (2007). Construction superintendent skill sets. Associated Schools of Construction International Proceeding of the $42^{\text {nd }}$ Annual Conference, Northern Arizona University - Flagstaff, Arizona.

Hauck, A. \& Jackson, B. (2005). Design and implementation of an integrated construction management curriculum. Associated Schools of Construction International Proceedings of the $41^{\text {st }}$ Annual Conference, University of Cincinnati-Cincinnati, Ohio.

Kemper, C. (1999). EQ vs IQ, Communication World, October/November, Vol.16, 15-19.

Kelting, S. \& Hauck, A. (2010). Project-based delivery system for an integrated residential construction course. Associated Schools of Construction International Proceedings of the $46^{\text {th }}$ Annual Conference, Wentworth Institute of Technology-Boston, Massachusetts.

Mills, T., Auchey, F., \& Beliveau, Y. (1996). The development of a vertically and horizontally integrated undergraduate building construction curriculum for the twenty first century. Journal of Construction Education, 1(1), 34-44.

Montoya, M., Kelting, S., \& Hauck, A. (2009). Pilot study of an integrated construction management curriculum. Associated Schools of Construction International Proceeding of the $45^{\text {th }}$ Annual Conference, University of FloridaGainesville, Florida.

Odusami, K. (2002). Perceptions of construction professionals concerning important skills of effective project leaders. Journal of Management in Engineering, April 2002, 18(2), 61-67.

Olbina, S. (2008). Improving the delivery system for teaching the project planning and feasibility/site development course to building construction undergraduate students and real estate graduate students. International Journal of Construction Education and Research, 4(1), 45-64.

Schon, D. (1983). The reflective practitioner. New York, NY: Basic Books

Senior, B. (1998). Infusing practical components into construction education. Journal of Construction Education, 3(2), 92-101.

Sirotiak, T. \& Walters, R. (2009). Improving student confidence and ability to cope under stress through project based learning. Associated Schools of Construction International Proceedings of the $45^{\text {th }}$ Annual Conference, University of Florida - Gainesville, Florida.

Thamhain, H. (1992). Engineering management: Managing effectively in technology-based organizations, $1^{\text {st }}$ Ed., Wiley, New York.

Wankat, P. \& Oreovicz, F. (1993). Teaching Engineering. New York, NY: McGraw-Hill, Inc.

Williams, K. \& Pender, G. (2002). Problem-based learning approach to construction management teaching. Journal of Professional Issues in Engineering Education and Practice, January 2002, 19-24. 


\section{Appendix A}

Table 1. Results of the students' evaluations

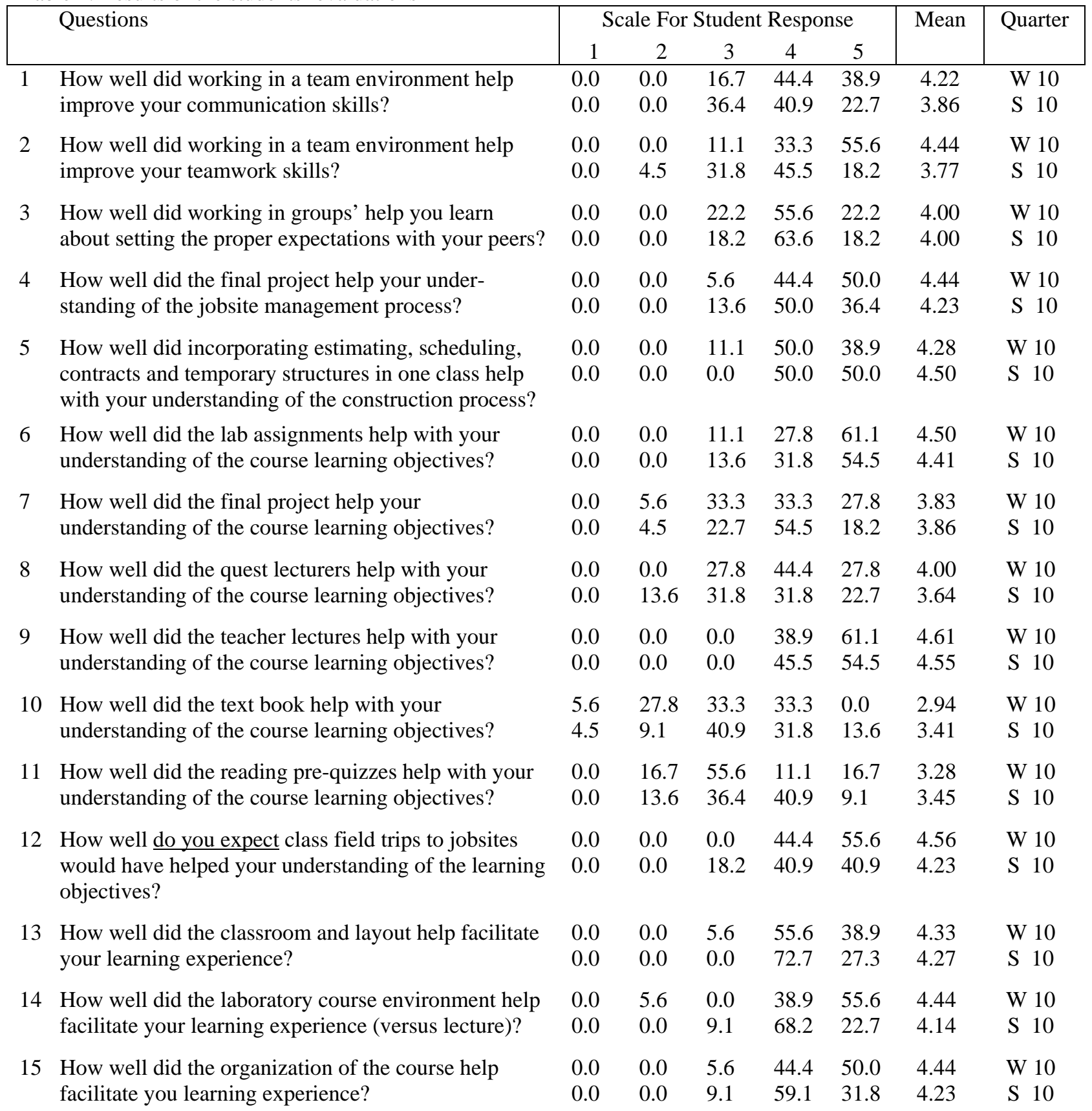

\section{Author Notes}

The author like to encourage anyone who is interested in project-based learning, integrated curriculum delivery, and/or varying teaching methods in construction management education to please contact me to share ideas or experiences at: plbarlow@calpoly.edu. 